\title{
Aortic Valve Annulus
}

National Cancer Institute

\section{Source}

National Cancer Institute. Aortic Valve Annulus. NCI Thesaurus. Code C130167.

A fibrous membrane that attaches to, and provides support for, the aortic valve leaflets. 